\title{
Interactive comment on "Estimates of tree root water uptake from soil moisture profile dynamics" by Conrad Jackisch et al.
}

\section{Jesse Nippert}

nippert@ksu.edu

Received and published: 14 January 2020

Here the authors use detailed TDR measurements at consecutive depths in the soil profile to infer changes in water uptake by several beech trees on varying substrates. The authors compile a rigorously quantitative set of complimentary data (including sap flux from target trees) to validate the fluxes derived from the soil moisture measurements. Generally, the 'root water uptake' metric derived from soil moisture was similar to sap flux estimates, particularly during periods with greater water availability and on the sandy site. The goal of this study - develop a new metric to provide detailed water-use / transpiration estimates in complex canopies - is novel, rigorous, and has tremendous potential for more detailed ecological investigations.

Printer-friendly version

Discussion paper 
I have few major concerns or suggestion revisions for the authors to address. My most noteworthy suggestion for the authors is to simply / clarify this manuscript whenever possible. This is an extraordinarily detailed and jargon-rich manuscript that needs to be simplified. I'm a scientist that studies plant-water use (so in theory, this manuscript is directly within my field of study) and yet I found myself reading and re-reading sections to try to understand what was done, what the data means, and how the authors derived their conclusions. For many of the figures, I was never able to gain a full appreciation of what was conveyed (what exactly am I seeing in Figures 11 and 12?) and the legends were often non-descriptive (see Fig. 4 for an example). Thus, I encourage the authors to reduce the jargon, better explain the development of the RWU calculation, and simplify the figures whenever possible. The novelty and creativity of this manuscript is in the top $95 \%$, but the clarity and delivery of the information is in the 50-60th percentile. I'm fully confident the authors can address this issue.

Other comments: The Introduction is generally sound, but there are a few items of concern. On page 1 line 17, the authors need to remove 'even over grasslands'. Grasslands are not definitely simpler ecosystems that forests, so please do not refer to them as such. On line 18, please address the 'optimise their water transport to respiration'. The optimality theory has been challenged many times since 2009, and in fact doesn't appear to be valid. In addition, why would water transport be optimized for respiration? I believe you meant assimilation. Regardless, please update.

Examples of RWU assessments in the literature are provided on page 2 . While I have never read an approach as detailed as the one presented here, transpiration dynamics have been assessed by comparing sap flux with changes in soil moisture dynamics previously. Please check out Holdo and Nippert 2015 Ecology (https://doi.org/10.1890/141986.1) for a study comparing transpiration dynamics using sap flux, soil moisture, isotopes, and changes in canopy temperature among coexisting trees and grasses.

On page $5 /$ line 7 , the authors note that sap flux was monitored in 4 trees near the TDR probes at each site. Do subsequent sap flux data (Fig. 3, 5, 6, etc) represent a single

Printer-friendly version

Discussion paper
Interactive comment 
tree, or an interpolation across all 4 trees per site?

Page 5, line 22. 'Efficiency' is misspelled.

Section 3 describes Fig. 3, and the derivation of RWU based on soil moisture step change. How was this 3 day period selected? Can I assume it was the best 3-day period where a step change was observed during this summer? Does the lower correlation in RWU time series (and during drier times) reflect derivation of the metric during an ideal period, which then loses predictive power during mean summer soil moisture periods?

When linking RWU from TDR data to transpiration dynamics from an individual tree, how did you account for water use by the understory vegetative community? Unless there were no grasses, forbs, saplings, etc. - wouldn't these species be using water from the same soil depths which would then complicate predictions of individual tree water-use using changes in soil moisture? The methods section does not describe the understory.

On the sandy site, how did you account for capillary action within the soil profile and subsequent evaporation? Or do you have some information (which I may have missed) on evaporation rates, and the depths of the evaporative fronts from these soils?

Fig. 6 is an impressive behemoth. One item of interest to me is that the rainfall history does not appear to have any temporal synchrony with RWU or sap flux. Is this true? And if so, why not? In Fig. 7, how does these predictions of water use in $\mathrm{mm} /$ day compare to estimates of Beech from similar locations within the literature. It would be nice to know if these predictions fall in the range reported elsewhere.

Page 14, line 9 - I don't think 'ambivalent' is the correct term. An ambivalent picture suggests this was inconclusive research. You concluded many things, and illustrate a path forward for using soil moisture to infer plant water use.

Printer-friendly version

Page 17, line 5. How do you know it's a minor effect? HR can be quite substantial in

Discussion paper 
many ecosystems.

Page 17, line 14 - How would cosmic ray measurements be appropriate here? I was under the impression that cosmic ray data pertains to the top $10 \mathrm{~cm}$ of the soil only.

In the Discussion section, the authors note that RWU and sap flux were not interchangeable, but were complementary. The language infers that RWU may be more desirable than sap flux for estimating transpiration under certain conditions. This seems a bit misleading to me. Sap flux directly measures a physiological process that relates to canopy transpiration, while RWU is an inferred metric. Under what conditions would the data from RWU be preferred over sap flux? Under what conditions does RWU outperform sap flux for predictions of transpiration?

Interactive comment on Biogeosciences Discuss., https://doi.org/10.5194/bg-2019-466, 2019. 